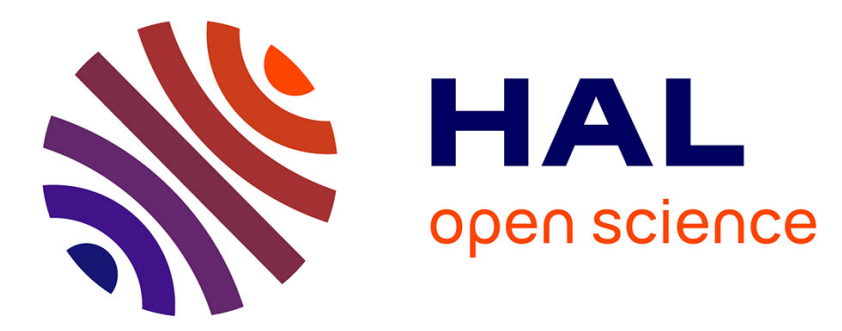

\title{
Ionospheric signatures of plasma injections in the cusp triggered by solar wind pressure pulses.
}

\author{
Jean-Claude Cerisier, Aurélie Marchaudon, Jean-Michel Bosqued, Kathryn \\ Mcwilliams, Harald U. Frey, Mehdi Bouhram, Harri Laakso, Malcolm Dunlop, \\ Matthias Förster, Andrew Fazakerley
}

\section{To cite this version:}

Jean-Claude Cerisier, Aurélie Marchaudon, Jean-Michel Bosqued, Kathryn Mcwilliams, Harald U. Frey, et al.. Ionospheric signatures of plasma injections in the cusp triggered by solar wind pressure pulses.. Journal of Geophysical Research Space Physics, 2005, 110 (A8), pp.A08204. 10.1029/2004JA010962 . hal-00156189

\section{HAL Id: hal-00156189 \\ https://hal.science/hal-00156189}

Submitted on 29 Jan 2016

HAL is a multi-disciplinary open access archive for the deposit and dissemination of scientific research documents, whether they are published or not. The documents may come from teaching and research institutions in France or abroad, or from public or private research centers.
L'archive ouverte pluridisciplinaire HAL, est destinée au dépôt et à la diffusion de documents scientifiques de niveau recherche, publiés ou non, émanant des établissements d'enseignement et de recherche français ou étrangers, des laboratoires publics ou privés. 


\title{
Ionospheric signatures of plasma injections in the cusp triggered by solar wind pressure pulses
}

\author{
Jean-Claude Cerisier, ${ }^{1}$ Aurélie Marchaudon, ${ }^{1,2}$ Jean-Michel Bosqued, ${ }^{3}$ \\ Kathryn McWilliams, ${ }^{4}$ Harald U. Frey, ${ }^{5}$ Mehdi Bouhram, ${ }^{6,7}$ Harri Laakso, ${ }^{8}$ \\ Malcolm Dunlop, ${ }^{9}$ Matthias Förster, ${ }^{10}$ and Andrew Fazakerley ${ }^{11}$ \\ Received 6 December 2004; revised 17 May 2005; accepted 23 May 2005; published 18 August 2005.
}

[1] We describe coordinated observations made on 14 July 2001 simultaneously in the midaltitude cusp by Cluster and at the cusp's ionospheric magnetic footprint by Super Dual Auroral Radar Network (SuperDARN) and Imager for Magnetopause-to-Aurora Global Exploration (IMAGE) during a period of three successive solar wind dynamic pressure pulses. In association with each of these pulses, Cluster observes plasma injections while auroral images from the IMAGE spacecraft show enhanced precipitation in the cusp. Following these plasma injections, channels of fast convection flows are observed in the ionosphere by the SuperDARN radars. On the basis of the spatial and temporal relationships between these various signatures, we analyze the response of the dayside magnetosphere and ionosphere to the pressure pulses as follows: (1) the solar wind dynamic pressure pulses are the drivers of plasma injections from the magnetosheath into the cusp; (2) the ionospheric convection bursts start shortly after the auroral intensifications and their duration is much longer (10 min versus 4-6 min for the auroral intensifications); (3) the convection bursts occur on the poleward side of the cusp precipitation; and (4) the Alfvén waves that are responsible of the transmission of the magnetic stress from the reconnection site to the ionosphere are strongly reflected in the upper ionosphere. This, in addition to possible parallel potential drops, may explain the imperfect mapping of the magnetospheric electric field into the ionosphere during the injections. These observations demonstrate that the convection bursts are "fossil" signatures of the compression-injection process, which is also a signature of reconnection at the dayside magnetopause driven by the interplanetary magnetic field alone.

Citation: Cerisier, J.-C., A. Marchaudon, J.-M. Bosqued, K. McWilliams, H. U. Frey, M. Bouhram, H. Laakso, M. Dunlop, M. Förster, and A. Fazakerley (2005), Ionospheric signatures of plasma injections in the cusp triggered by solar wind pressure pulses, J. Geophys. Res., 110, A08204, doi:10.1029/2004JA010962.

\section{Introduction}

[2] During sporadic reconnection events (flux transfer events or FTEs) at the dayside magnetopause, magnetosheath plasma enters the magnetosphere along cusp field lines. It is expected that these downgoing parallel plasma flows occur in conjunction with enhanced ionospheric convection events driven by the magnetic tension at the reconnection site. Associated optical auroral emissions result from enhanced precipitation of the magnetosheath

\footnotetext{
${ }^{1}$ Centre d'Etude des Environnements Terrestre et Planétaires, SaintMaur, France.

${ }^{2}$ Now at Mullard Space Science Laboratory, University College London, Dorking, UK.

${ }^{3}$ Centre d'Etudes Spatiales des Rayonnements, Toulouse, France.

${ }^{4}$ Institute of Space and Atmospheric Studies, University of Saskatchewan, Saskatoon, Saskatoon, Canada.

${ }^{5}$ Space Sciences Laboratory, University of California, Berkeley, California, USA.

Copyright 2005 by the American Geophysical Union. 0148-0227/05/2004JA010962
}

plasma. Such events have long been recognized as due to IMF variations, but the triggering role of solar wind pressure pulses has not been definitely established.

[3] Variations in the IMF orientation, which has been recognized as the main driver of magnetospheric and ionospheric convection, affect the rate and location of reconnection, either stationary or transient and localized. Auroral transients [Sandholt et al., 1993] moving poleward (called poleward moving auroral forms or PMAFs) have been observed extensively with meridian scanning photometers when the IMF is directed southward. Radar observations [Lockwood et al., 1990; Milan et al., 1999] have

\footnotetext{
${ }^{6}$ Max-Planck-Institut für Extraterrestrische Physik, Garching, Germany. ${ }^{7}$ Now at Centre d'Etude des Environnements Terrestre et Planétaires, Saint-Maur, France.

${ }^{8}$ Space Science Department, ESA/ESTEC, Noordwijk, Netherlands.

${ }^{9}$ Space Science and Technology Department, Rutherford Appleton Laboratory, Chilton, UK.

${ }^{10}$ Max-Planck-Institut für Extraterrestrische Physik, Garching, Germany.

${ }^{11}$ Mullard Space Science Laboratory, University College London, Dorking, UK
} 
demonstrated a close association with poleward and westward (or eastward) convective motion (called poleward moving radar auroral forms or PMRAFs) when IMF $B_{y}>$ $0(<0)$ in the Northern Hemisphere. It is now agreed that both are the footprint ionospheric signatures of newly reconnected flux tubes, the motion of which is controlled by magnetic tension.

[4] On the other hand, solar wind pressure variations are also responsible for a variety of magnetospheric processes, including the varying size of the magnetosphere and the associated storm commencement, the motion of magnetospheric boundaries triggering surface waves on the magnetopause, and the associated ionospheric convection and current vortices [Friis-Christensen et al., 1988, Glassmeier et al., 1989, Sibeck et al., 1989, 2003].

[5] The IMF direction and the solar wind pressure often vary simultaneously, making it difficult to separate their effects on the magnetosphere [Roelof and Sibeck, 1993; Song et al., 1994]. An equatorward motion of the ionospheric cusp is observed in response to both a southward turning of the IMF and to a pressure increase. In both cases, bipolar magnetic signatures at the magnetopause [Sibeck et al., 1989], ionospheric convection bursts, and auroral emissions are observed.

[6] In the ionosphere, two very different types of convective responses to pressure pulses have been observed. The first type has been described by Sibeck and Croley [1991] and Thorolfsson et al. [2000] who have observed flow transients (called pulsed ionospheric flows or PIFs) with a sunward velocity, occurring in the dayside ionosphere at latitudes equatorward of the convection reversal boundary. The second type, which is characterized by flow transients entering the polar cap in the cusp region, is similar to PMRAFs, the usual signature of FTEs. In a detailed case study, Sandholt et al. [1994] have shown that enhancements of the solar wind dynamic pressure give rise to an equatorward shift of the cusp/cleft aurora, to enhanced convection, and to auroral transients identical to the PMAFs associated with FTEs. The eastward longitudinal component of the enhanced convection velocity and the eastward motion of the auroral events were in the direction anticipated for reconnected flux tubes pulled by the magnetic tension for negative IMF By. Similarly, in a case study Farrugia et al. [1995] have found a good correlation between the arrival at Earth of upstream dynamic pressure pulses and auroral transients at the poleward edge of the persistent aurora. These transients were observed moving eastward from the cusp footprint, also in agreement with their driving by magnetic tension.

[7] The above auroral dayside transients, which are observed on opened cusp field lines, must not be mistaken with those produced by the compression of magnetospheric closed flux tubes, the latter leading to the precipitation of high-energy trapped particles by wave-particle interactions, as described, for instance, by Zhou and Tsurutani [1999].

[8] Recent Cluster ground-based studies have confirmed the close relationship between convection bursts in the ionosphere and reconnection at the magnetopause [Wild et al., 2001; Farrugia et al., 2004]. Marchaudon et al. [2004] compared the responses of the convection in the outer cusp and in the ionosphere to changes in the IMF By and during
PMRAFs, showing that the ratio of the observed convection velocities is consistent with the hypothesis of mapping along equipotential field lines.

[9] This paper is an extension of a previous case study of plasma injections from the magnetosheath into the magnetosphere, triggered by solar wind pressure pulses [Bosqued et al., 2005, hereinafter referred to as BEF]. In that study, Cluster multipoint measurements in the midaltitude cusp ( $\sim 5 R_{E}$ geocentric distance) on 14 July 2001 have been combined with global images from the IMAGE-SI-12 instrument during a period of southward and strongly duskward IMF. The solar wind pressure was highly variable and reached $13 \mathrm{nPa}$. Multiple, impulsive energy-dispersed ion injections from the magnetosheath are perfectly correlated in space and time with intense Ly $\alpha$ brightenings. These transient signatures demonstrate a one-to-one correspondence to solar wind pressure enhancements, each leading to an equatorward shift of the UV aurora. Using a multipoint analysis, it was shown that the newly reconnected flux tubes were moving westward, as expected for motion controlled by the magnetic tension during positive IMF $B_{y}$. Their velocity was very high, up to $\sim 50 \mathrm{~km} / \mathrm{s}$ during their initial phase, which is equivalent to $\sim 5 \mathrm{~km} / \mathrm{s}$ when mapped to the ionosphere. Upward field-aligned currents carried by suprathermal cusp electrons were also identified on the poleward edge of the tube, in agreement with FTE models. These transient features have been interpreted by BEF as signatures of increased localized magnetic reconnection occurring on the dusk flank of the compressed magnetosphere at the antiparallel merging site. Another unambiguous result is that the reconnection rate does not vary spontaneously but responds directly to variations in the upstream dynamic pressure in addition to changes in the IMF polarity.

[10] In the present paper, we extend the above study by analyzing the Cluster and IMAGE results in relation with convection measurements made by SuperDARN radars at the ionospheric footprint of Cluster. We describe the relationship in space and time between the auroral and convection signatures in the ionosphere, in order to demonstrate the persistence of the flow bursts after the injection. We also compare the convection velocities measured in the ionosphere during the injection events with the electric field and convection measurements at Cluster, and we discuss the possible sources of the observed discrepancies in terms of static and Alfvén wave fields. We also confirm the interpretation given by BEF that the pressure pulses are the drivers of magnetic reconnection and plasma injections from the magnetosheath.

\section{Overview of the Event}

\subsection{Instrumentation}

[11] The Cluster mission, composed of four identical spacecraft in tetrahedral formation, travels in an elliptical orbit, with a perigee of $4 \mathrm{R}_{\mathrm{E}}$, an apogee of $19.6 \mathrm{R}_{\mathrm{E}}$ and a period of 58 hours. In this paper, we use data from the following experiments: the Cluster Ion Spectrometer (CIS) experiment [Rème et al., 2001], which measures the injections of magnetosheath ions into the cusp; the Fluxgate Magnetometer experiment (FGM) [Balogh et al., 2001]; the Electron Drift Instrument (EDI), measuring the local 


\section{SUPERDARN FIELD-OF-VIEW (Geomagnetic Coordinates)}

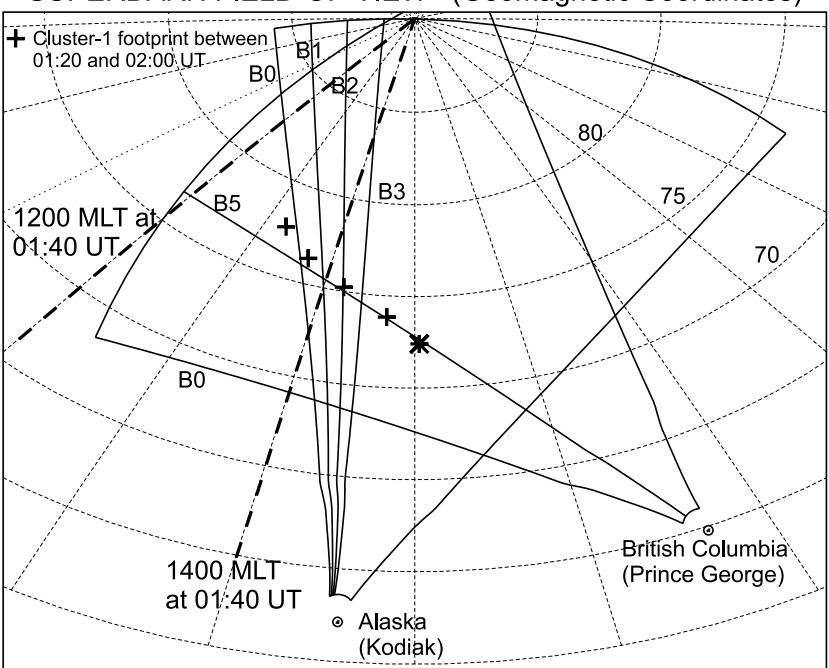

Figure 1. Geometry of the conjunction. The field-of-view of the British Columbia (Prince George) and Alaska (Kodiak) radars are shown with the direction of pertinent beams. The foot points of Cluster- 1 at $10 \mathrm{~min}$ time intervals between 0120 and 0200 UT are also indicated.

convection velocity [Paschmann et al., 2001]; the Plasma Electron And Current Experiment (PEACE) [Johnstone et al., 1997]; and the Electric Field and Wave (EFW) experiment [Gustafsson et al., 1997].
[12] The SuperDARN HF radars [Greenwald et al., 1995] monitor the convection of the ionospheric plasma. They measure the radial component of the plasma velocity in 75 range gates per beam and perform azimuthal scans over 16 beam directions. During the interval of interest, the radars were operating in a high-resolution mode, in which a full scan was performed every minute. The radars used in this study are the British Columbia (at Prince George) and Alaska (at Kodiak) radars which share a common field-ofview, thus allowing vector velocity measurements to be made. The geometry of the fields of view of the radars is shown in Figure 1 in magnetic (Mlat, MLT) coordinates.

[13] The Far Ultra-Violet (FUV) imager onboard the IMAGE satellite includes three instruments [Mende et al., 2000] that provide two-dimensional images of the auroral oval. Images from two of these instruments are used in this paper: the Wideband Imaging Camera (WIC) and the Spectrographic Imager (SI). WIC measures in the wavelength range from 140 to $180 \mathrm{~nm}$, which includes $\mathrm{N}_{2}$ emissions. SI is sensitive to Doppler shifted Lyman- $\alpha$ emission resulting from charge exchange with precipitating protons with energies above $1.0 \mathrm{keV}$. Auroral images are obtained every two minutes.

\subsection{Geometry of the Conjunction}

[14] During summer 2001, the perigee of the Cluster orbit was located on the dayside. At perigee, the Cluster tetrahedron is strongly distorted, as shown on Figure 2. Cluster-1, -2 and -4 were close to one another, and Cluster- 3 lagged on the same orbit with a delay of 40-50 min. On

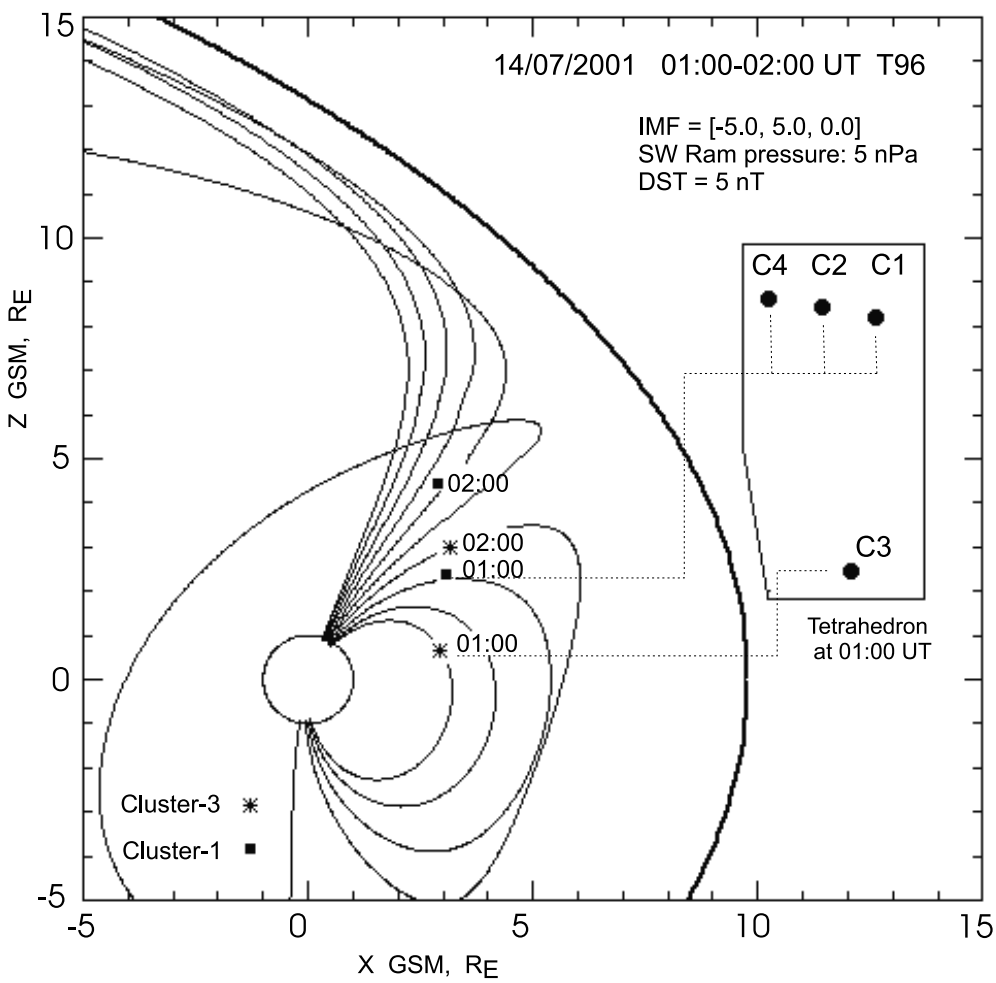

Figure 2. Projection of the Cluster orbit on the XZ GSM plane between 0100 and 0200 UT on 14 July 2001. Stars show the positions of Cluster-1-2-4, while squares show the positions of Cluster-3. An enlarged view of the Cluster tetrahedron at 0140 UT is shown on the right. The field lines were computed using the T96 magnetic field model. 

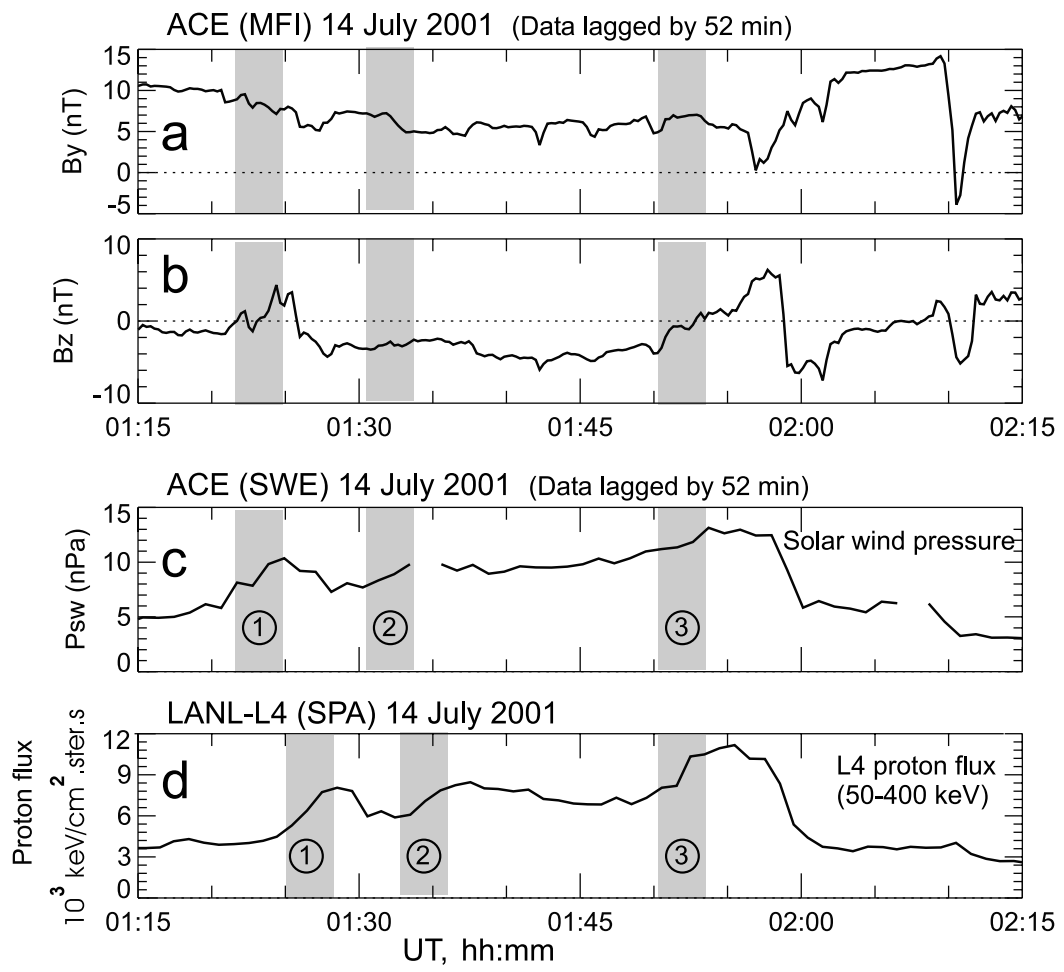

Figure 3. Solar wind and IMF conditions measured by the ACE satellite. (a and b) Interplanetary magnetic field GSM $y$ and $z$ components. (c) Solar wind pressure. (d) Energetic proton flux at LANL-L4.

14 July, the satellites flew poleward across the midaltitude (4-5 $\mathrm{R}_{\mathrm{E}}$ ) cusp, through the 1500 to 1300 magnetic local time (MLT) sector. Mapped into the ionosphere along magnetic field lines according to the T96 model [Tsyganenko, 1995], the Cluster footprint moved poleward and westward in the common field-of-view of the SuperDARN radars along beam 5 of the British Columbia radar and across beams 5 to 0 of the Alaska radar (see Figure 1). During the whole period of interest, the IMAGE satellite provided FUV images of the northern auroral oval.

\subsection{Interplanetary Conditions}

[15] On 14 July 2001, the mean dynamic pressure of the solar wind impacting on the magnetosphere was high, with large variations between 0115 and 0215 UT. During this period, three successive pressure increases occurred, followed by a sharp decrease. These variations were initially observed at the L1 position by ACE, and subsequently through the responses which they generate on ground magnetometers (not shown) and in the magnetosphere at the geostationary orbit and observed by the LANL-L4 satellite around 0900 MLT (Figure 3). The variations of the flux of trapped high-energy protons at the geostationary orbit follow very clearly the variations of the solar wind pressure. This allows one to estimate the variable time delay between ACE and the magnetosphere with a high precision. As shown on Figure 3, the delay is not constant but varies from $56 \mathrm{~min}$ for the first pressure pulse to $52 \mathrm{~min}$ for the third pressure pulse and the pressure decrease. This fourminute variation in the delay is partly explained (1.6 min) by the slight increase in the solar wind velocity during the period, the remainder having to be attributed either to the changing size of the magnetosphere or to the changing orientation of the pressure front. Thus the ACE data in the top panels of Figure 3 have been delayed by $52 \mathrm{~min}$. The LANL-L4 data show that the three positive pressure pulses reach the magnetosphere at 0128,0137 and 0153 UT respectively (shaded zones on Figure 3). Shortly after the third pulse, the solar wind pressure decreased abruptly at 0158 UT. The times of arrival observed at LANL-L4 will be considered as also representing the times of arrival at Cluster.

[16] During the period under study, the IMF is fairly stable, dominated by a large positive dawn-dusk component (between 5 and $10 \mathrm{nT}$ ) and with a small southward component. $B z$ was slightly negative, between -2 and $-4 \mathrm{nT}$, with two short positive periods at the times of the first and third pressure pulses. Because, as it will be shown later, all three positive pressure pulses result in similar ionospheric signatures despite the IMF variations being slightly different, we will consider that the solar wind pressure increases are the main factor controlling the dayside magnetospheric plasma injections.

\subsection{Convection: SuperDARN}

[17] During the period when pressure pulses occur, the common field-of-view of the British Columbia and Alaska radars covered the auroral zone in the 1200-1700 MLT sector. As shown in Figure 1, the Alaska beams of interest are directed mainly northward, while beam 5 of British Columbia is directed in the northwestward direction.

[18] Figure 4 shows the range-time plots of the radial velocity and backscattered power for beam 0 of the Alaska radar and for beam 5 of the British Columbia radar during the period 0115-0215 UT. Beam 1 data from the Alaska radar are also displayed in the top panels of Figure 5. 


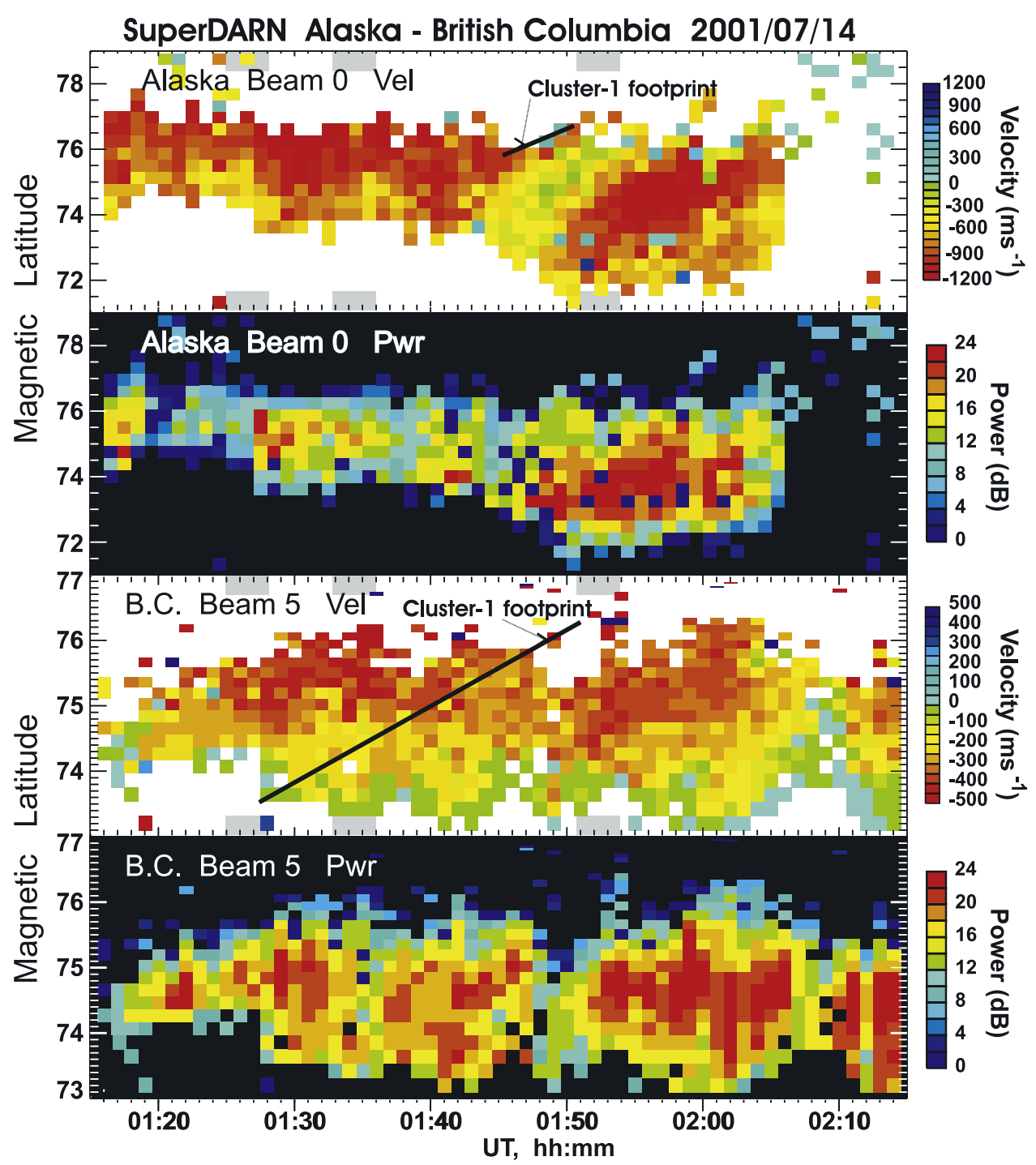

Figure 4. SuperDARN range-time plots of the radial velocity and backscattered power for beam 0 of the Alaska radar and for beam 5 of the British Columbia radar. Negative velocities are away from the radar. Different color scales are used for the Alaska and British Columbia velocity plots. The gray zones at the top of the velocity panels indicate the periods of strongest magnetospheric compression deduced from LANL-L4 data. The ionospheric footprint of Cluster-1 is indicated by black lines on the velocity panels.

Negative (green to red) velocities are away from the radars. At Alaska, bursts of large velocities $(\sim 1000 \mathrm{~m} / \mathrm{s}$ and up to $1200 \mathrm{~m} / \mathrm{s}$ on beam 0 ) occurred in association with the positive pressure pulses observed at LANL-L4 (indicated by the gray-shaded zones at the top and bottom of the velocity panels). To assess more quantitatively this effect, the Alaska radial averaged velocity from beams 0 and 1 and from range gates between 74.5 and $76.5^{\circ}$ Mlat is shown in Figure 5c. Each solar wind pressure pulse was followed by an increasingly negative (poleward) velocity starting at 0125, 0135 and $0150 \mathrm{UT}$, respectively. Clearly, the third pulse appears to have had the strongest effect on the convection, while the effect of the second pulse is the weakest. The effect of these solar wind pressure variations on the reconnection rate has been already discussed and explained by BEF, in terms of variations in the Alfvén Mach number and in the plasma $\beta$ in the magnetosheath. The velocity bursts are essentially northward, as indicated by the much smaller velocities observed at British Columbia (which looks predominantly westward) than at Alaska (which looks northward). This northward direction will be quantified later when merging the data from both radars. These northward flows represent plasma entering the polar cap in the 1300 MLT sector, corresponding to the cusp for positive IMF $B y$. These poleward flows are fed by sunward flowing plasma observed at later MLTs, i.e., on the eastern beams of Alaska, in agreement with the asymmetric twocell convection pattern for positive IMF $B y$.

[19] Each velocity burst is also associated with an increase in the backscattered power. During the period including the three positive pressure pulses, between 0120 and 0155 UT, the low latitude boundary of the radar echoes moves equatorward significantly. Although the amplitude of the motion is larger, this is likely related to the equatorward 

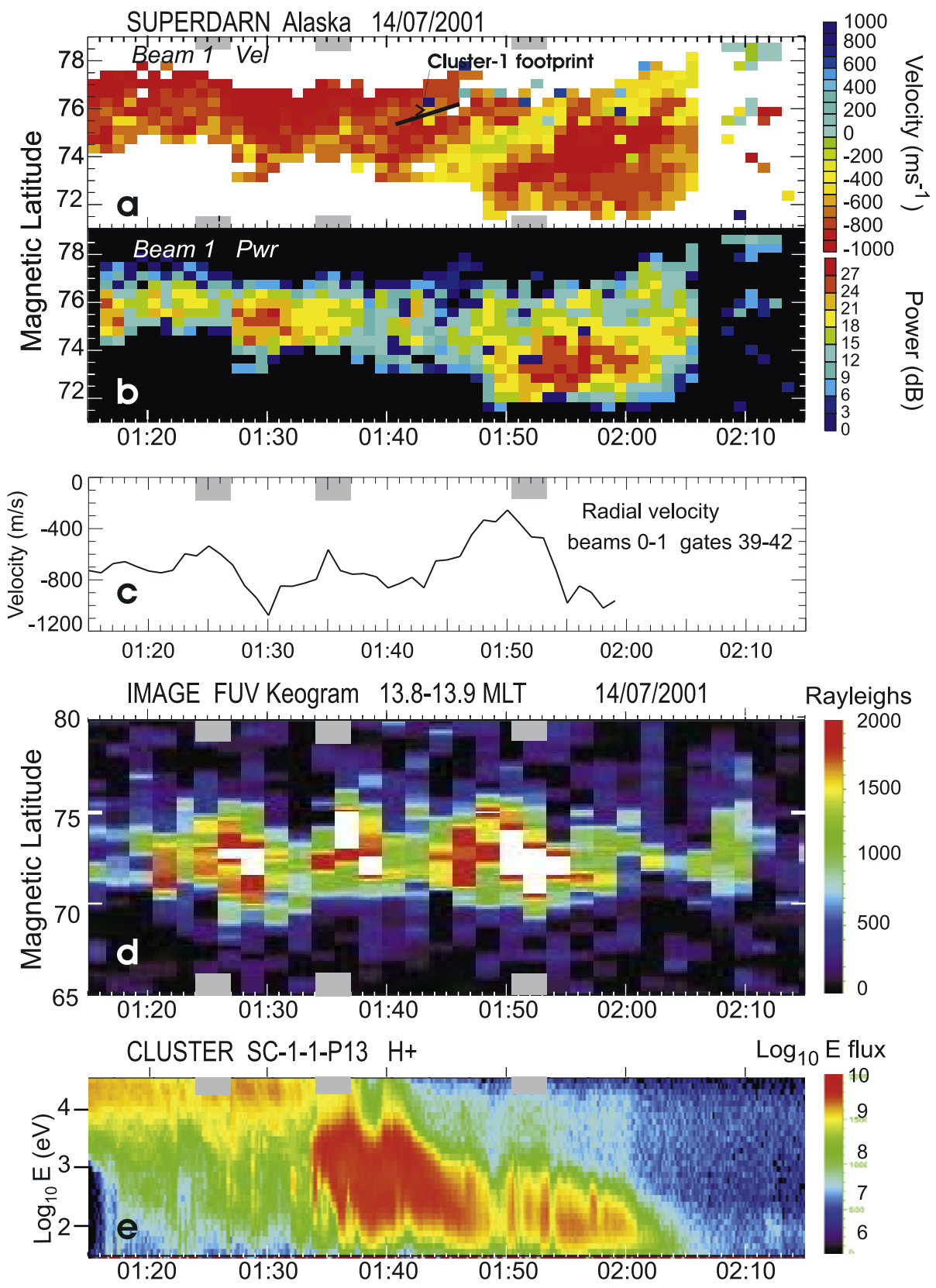

Time, hh:mm

Figure 5. Time variation of the convection velocity, auroral emissions, and particle injections. (a and b) SuperDARN range-time plots of the radial velocity and backscattered power for beam 1 of the Alaska radar. The ionospheric footprint of Cluster-1 is indicated by a black line on Figure 5a. (c) Alaska radial velocity averaged on beams 0 and 1 and between $74.5^{\circ}$ and $76.5^{\circ}$ magnetic latitude. (d) IMAGE keogram at 13.8 MLT. The resolution is $0.5^{\circ}$ in latitudinal width and 0.1 hour in MLT. White pixels indicate an intensity larger than 2 Rayleighs. (e) Cluster-1 CIS spectrogram of downgoing protons. The gray zones in Figures $5 \mathrm{a}, 5 \mathrm{c}, 5 \mathrm{~d}$, and $5 \mathrm{e}$ indicate the periods of strongest magnetospheric compression deduced from LANL-L4.

motion of the aurora described by BEF and explained in terms of solar wind pressure increases, which result in a compression of the magnetosphere and an equatorward motion of the ionospheric cusp [Newell and Meng, 1994, Sandholt et al., 1994].
[20] In the velocity and power plots, the bursts demonstrate the main characteristic of PMRAFs, namely a phase motion away from the radar. Although the bursts overlap, due to the limited time resolution of SuperDARN, the slope of the structures is evident in the range-time plots of 
Figure 4. This allows us to deduce an apparent "phase velocity" defined by $\delta$ (range) $/ \delta t$. The values obtained from the most clearly identified structures in the Alaska data range between $900 \mathrm{~m} / \mathrm{s}$ (beam 0) and $800 \mathrm{~m} / \mathrm{s}$ (beam 3 ) for the PMRAFs triggered by the first two pulses and $650-800 \mathrm{~m} / \mathrm{s}$ for the third pulse. Along beam 5 of the British Columbia radar, the phase velocity is $600 \mathrm{~m} / \mathrm{s}$.

[21] The abrupt change in the occurrence rate of backscattered echoes for the Alaska radar at 0206 UT was an instrumental effect due to an automatic change in the operating frequency of the radar.

\subsection{Auroral Emissions and Particle Injections: IMAGE and Cluster}

[22] Between 0100 and 0200 UT auroral intensifications in the early afternoon MLT sector were observed by the Far Ultra Violet (FUV) camera onboard the IMAGE satellite. These intensifications occurred in association with the solar wind pressure pulses. Figure $5 \mathrm{~d}$ shows, in addition to the Alaska radar beam 1 radial velocity and backscattered power, the closest IMAGE keogram in the 13.8-13.9 MLT sector. The resolution of the keogram is $0.5^{\circ}$ in latitudinal width and 0.1 hour in MLT. The figure clearly displays the time synchronism between the three radial velocity bursts, the three auroral intensifications and the three pressures increases (indicated by the gray-shaded zones at the top of the velocity and keogram panels). For the first pulse, the sharp increase in the auroral intensity occurred between 0124 and 0126 UT, while the strong pressure increase started at 0125 UT. Similarly, for the third pulse, the main pressure increase occurred between 0150 and 0153 UT, following a slower increase starting around 0145 UT (Figure 3). The auroral intensity (Figure 5) also shows a faint intensification up to $0150 \mathrm{UT}$ when the intensity increases suddenly. The association of the auroral intensifications in the cusp with the compression of the magnetosphere is confirmed by the fact that IMAGE observes auroral intensifications also at other MLTs, on the dawn side (0400-0500 MLT sector) and dusk side (18001900 MLT sector) auroral zone with a 2- to 4-min delay after the cusp intensifications, indicating a downstream propagation of the compression of the magnetosphere with the solar wind flow.

[23] Inside each burst, both the auroral intensity and the low-latitude limit of the radar echoes move southward. Three important differences between the velocity bursts and the auroral intensifications should be noted, however: (1) the auroral emissions are centered between 72 and $74^{\circ}$ Mlat, while the low latitude boundary of the flow bursts is about $74^{\circ}$ Mlat and the bursts extend up to $80^{\circ}$ Mlat; (2) the duration of the auroral intensifications (typically 2-4 min) is much shorter than the duration of the flow bursts (typically $10 \mathrm{~min}$ or more); (3) the auroral emission remains at a nearly constant latitude range while flow bursts propagate poleward.

[24] From the drop-off in the energetic trapped electron flux, it has been shown by BEF, that Cluster-1 crossed the boundary between closed and opened field lines (OCB) at 0121 UT $\left(71.7^{\circ}\right.$ Mlat). Figure 5e displays the time variation of the omnidirectional proton flux measured by the Cluster1 CIS1 experiment. At the time of the first pressure pulse, Cluster-1 was situated equatorward of the cusp and did not see the associated injections, which were seen, however, by the more poleward Cluster- 4 as noticed by BEF. Cluster- 1 entered the cusp around 0133 UT and clearly saw several injections of magnetosheath plasma associated with the second pulse. These injections will be described in more detail later. At the time of the third pressure pulse, Cluster-1 was entering the polar cap and saw only a faint injection, although the IMAGE data show that it is the most intense of the three events.

\section{Discussion}

\subsection{Convection and Auroral Emissions}

[25] By comparing the responses of the convection and aurora to the solar wind pressure pulses it becomes possible to describe how these signatures are related in space and time. In the time domain, the auroral intensifications start between 1 and 2 min before the convection bursts. The duration of the auroral intensifications $(4-6 \mathrm{~min}$ ) is also, and most importantly, much shorter than the duration of the flow bursts $(10 \mathrm{~min})$. In the space domain, the auroral intensifications occurred systematically at lower latitudes (typically between 72 and $75^{\circ}$ Mlat) than the flow bursts, and the high-latitude limit of the aurora corresponded roughly to the low-latitude limit of the flow bursts. We have chosen to illustrate this last point with the first solar wind pressure pulse (0128-0129 UT), when beams $0-3$ of the Alaska radar were well-centered on the cusp precipitation. Figure 6a shows an IMAGE FUV-WIC intensity map superposed with the global convection pattern deduced from the full set of Northern Hemisphere SuperDARN radars [Ruohoniemi and Baker, 1998; Shepherd and Ruohoniemi, 2000]. The electron cusp precipitation occurs in the region where the convection rotates from a predominantly sunward longitudinal flow into a poleward accelerated flow entering the polar cap. Figures $6 \mathrm{~b}$ and $6 \mathrm{c}$ show, for the same time period as Figure 6a, the IMAGE FUV-SI contour map superposed with the Alaska and British Columbia radial velocity maps, respectively. For both radars the convection bursts clearly occurred on the poleward side of the cusp precipitation. The sunward flowing plasma feeding the cusp was observed at later MLTs on the eastern beams of Alaska (positive velocities on Figure 6b). The explanation for the absence of radar measurements in the precipitation region, where the rotation of the flow occurs, is unclear. It may be due to propagation conditions or increased absorption.

[26] The above observations show that the relationship between the motion of the flux tube supporting the injections and the northward propagating convection burst is complex. One could speculate that the brightenings of the dayside aurora are not necessarily associated with enhancements of the reconnection rate, but more with changes in the flux of particles crossing the magnetopause due to the increased solar wind density. In favor of this hypothesis is the fact that the pressure increases are due to increases in the density of the solar wind (which does not change the merging electric field), more than to increases in the velocity. However, this hypothesis has been rejected by BEF essentially on the basis of Cluster observations of ion steps and upward parallel currents, which are strongly indicative of the "pulsed reconnection" interpretation. 

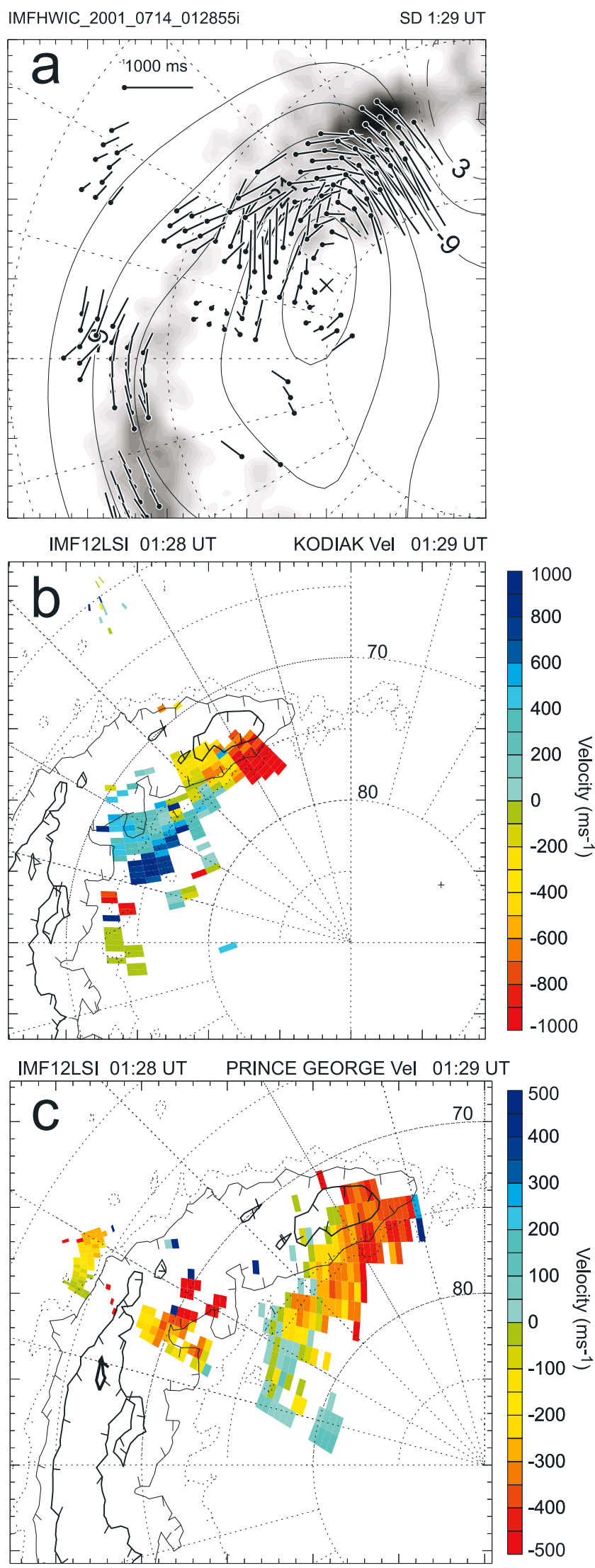

[27] In this "increased reconnection" framework, the SuperDARN observations suggest that the life of a reconnected flux tube includes two periods. During the first period the magnetosphere is compressed and magnetosheath particles are injected in the cusp. Although magnetic tension is already present, this period is characterized by an equatorward motion of the footprint of the reconnected flux tube. This motion appears clearly in each burst in the 13.8 MLT FUV/SI-12 keogram of Figure 5d. It can also be seen in the radial velocity and backscattered power data of the Alaska radar for the first and third pressure pulses (Figures 4 and 5). This equatorial motion of the ionospheric cusp is attributed to the increased compression of the magnetosphere [Frey et al., 2003]. When the injection has stopped, during the second period, the reconnected flux tube was dragged antisunward into the polar cap by the magnetic tension and the solar wind flow around the magnetosphere. There may be, however, an overlap between the first and the second periods, the poleward motion of the flux tube starting before the end of the injection. In this scenario, it appears that the convection burst is, at least during most of its lifetime, a fossil signature of the injection.

[28] It must also be noticed (Figure 5d) that only a weak equatorward motion of the Ly $\alpha$ emission is observed from one pulse to the next. From a detailed analysis, BEF (their Figure 5d) deduced a mean motion of $0.5^{\circ}$ between the first and the third pulse. As suggested by Milan et al. [2003], the addition of open flux increases the size of the polar cap and moves its boundary equatorward. The quasi-recovery in the position of the cusp from one pulse to the next may be attributed to the fast redistribution of the added flux to the entire polar cap.

[29] Another clear observation from Figures 4 and 5 is that the largest convection velocities are observed on the poleward side of the region of the radar echoes. This means that the modulus of the convection velocity inside the bursts tends to increase when the bursts move away from the injection region. The explanation of this acceleration may be found in the decreasing ionospheric conductivity at the bottom of the reconnected flux tube when it moves away from the active injection region.

[30] In cases of reconnection at the magnetopause triggering FTE events that are not associated with pressure pulses, several similar observations have been reported. McWilliams et al. [2001] showed that convection bursts (which they call "pulsed ionospheric flows" or PIFs) had a phase velocity that was larger than the convection velocity at the beginning of their lifetime and that decreased with time. On the basis of this evolution of the velocity, they suggested that the initial period was associated with active reconnection, and during the second period the reconnected flux tube was dragged by magnetic tension and the solar wind flow. Provan et al. [2002] have observed that the PIFs

Figure 6. IMAGE FUV and SuperDARN maps during the first solar wind pressure pulse (0128-0129 UT). (a) Wideband imaging camera image and convection vectors in the 1200-1800 MLT quadrant. (b) Spectrographic imager channel and Alaska radial velocities. (c) Spectrographic imager channel and British Columbia radial velocities. 


\section{SUPERDARN VELOCITY MAP (Merged vectors) Kodiak / British Columbia}
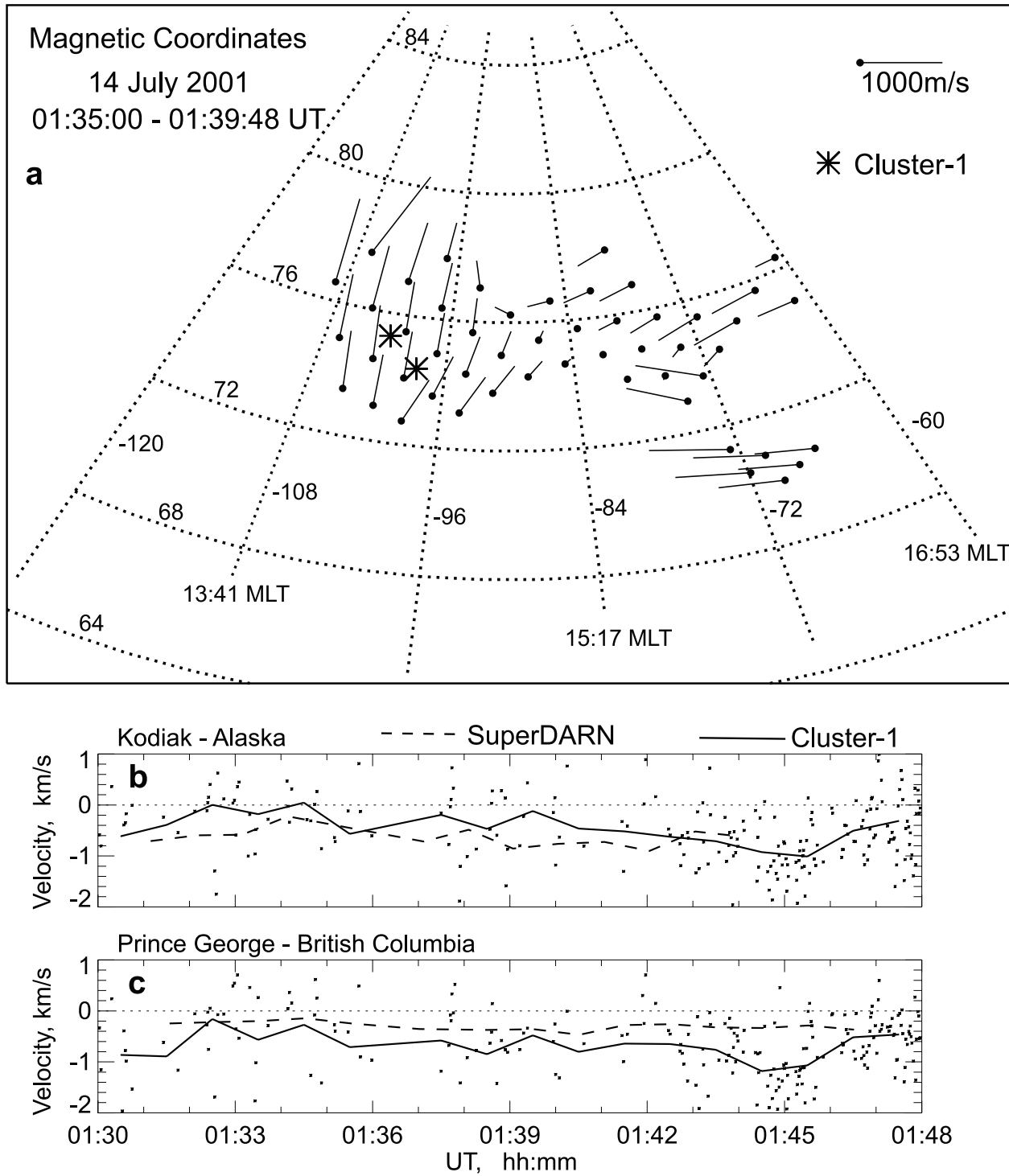

Figure 7. (a) Velocity vectors calculated from the two radar data sets during the second pressure pulse (0135-0140 UT). The ionospheric footprint of Cluster-1 at the beginning and end of the period is indicated by asterisks. (b) Radial component of the convection velocity (negative values are away from the radar) measured by SuperDARN (dotted line) and velocity measured by the EDI experiment on Cluster-1 (solid line and dots) after mapping to the ionosphere and projection along the Alaska beam. The solid line represents one-minute averages of individual EDI measurements (dots). (c) Same as Figure 7b for the British Columbia radar.

occur at a slightly higher latitude than the ion injections which characterize the newly opened flux tubes. Davies et al. [2002] also proposed a two-stage process in which poleward flow carries with it ionospheric ionization gradients which have been produced earlier by particle injection during the initial reconnection phase.

\subsection{Convection in the Magnetosphere and in the Ionosphere}

[31] We now focus on the second pressure pulse (01350143 UT) during which Cluster-1 was crossing the cusp with its magnetic footprint in the field-of-view of both the Alaska and British Columbia SuperDARN radars. Figure 7a shows the SuperDARN velocity vectors obtained by merging the radial velocities measured by the two radars after averaging over 5 successive scans between 0135 and 0140 UT. The position of Cluster-1 at the beginning and end of the period is indicated by asterisks, showing that the Cluster-1 footprint crossed the region of poleward ionospheric flow on the northern side of the main precipitation zone, where the average convection velocity is strictly northward and of the order of $800 \mathrm{~m} / \mathrm{s}$. Note also that the modulus of the average velocity tends to increase with increasing latitude, as already discussed.

[32] We will now compare the perpendicular plasma velocity measured at Cluster by the EDI experiment with the convection velocity measured by SuperDARN. For this comparison, the Cluster EDI vector velocities are first 
mapped to the ionosphere along isopotential field lines, and then projected along the SuperDARN beams carrying the footprint of Cluster according to the technique developed by Marchaudon et al. [2004]. Dots represent individual EDI measurements, while the solid line shows averages over 60 seconds s (equal to the time resolution of SuperDARN radial velocity measurements, and corresponding to a spatial averaging over $\sim 16 \mathrm{~km}$ in the ionosphere, a distance much smaller than the width of a SuperDARN cell). A word of caution is necessary concerning the differences in averaging. The 60 s time average of Cluster EDI data has smoothed out the small-scale fluctuations which appear in the dispersed individual measurements. It is important to note also the presence of gaps in EDI data during the injection events where convection measurements suffer from the background created by the natural plasma electrons at the beam energies (typically 0.5 or $1.0 \mathrm{keV}$ ). In other words, the EDI experiment provides reliable convection measurements at Cluster outside of the injection events. At SuperDARN, the sampling rate is also $1 \mathrm{~min}$, with each measurement averaged in time only over the $3 \mathrm{~s}$ integration period for the corresponding beam direction. At SuperDARN, the smoothing is thus essentially spatial over the radar cell, typically $45 \mathrm{~km} \times 80 \mathrm{~km}$. Although slight differences can be observed between Cluster and SuperDARN, the agreement is satisfactory. Both velocities, close to $800 \mathrm{~m} / \mathrm{s}$, agree quite well for the Alaska radar, particularly around 0142 UT, which corresponds to the end of the injections related to the second pressure pulse. During the injection period, the agreement between EDI and SuperDARN is less satisfactory, at least partly for the reasons stated above. The comparison between EDI and the British Columbia radar shows that the SuperDARN velocities are half of the EDI values. Owing to the orientation of beam 5 of the British Columbia radar, this is an indication of a smaller longitudinal component in the ionosphere than in the magnetosphere.

\subsection{Plasma Injections in the Cusp}

[33] Figure 8 shows an expanded view of Cluster-1 data during the second pressure pulse. PEACE (Figure 8a) and CIS (see also BEF, their Figure 6) show that a series of three plasma injections occurred during that period, between 0135:30 and 0137:00 UT, between 0139:00 and 0140:30 UT, and between 0141:30 and 0142:30 UT. Figures $8 \mathrm{~b}$ and $8 \mathrm{c}$ shows that the injections correlate with short periods of large DC electric field of the order of $10-15 \mathrm{mV} / \mathrm{m}$ and lasting typically $1 \mathrm{~min}$, which are consistently deduced from the CIS through the ion transverse drift and from the electric field (EFW) experiments. For the reasons already mentioned, EDI did not collect good observations during the injections. If mapped into the ionosphere, the electric fields would produce short longitudinal convection velocity pulses of $2-3 \mathrm{~km} / \mathrm{s}$ which are not observed by the SuperDARN radars. It could be argued that this is due to the one-minute time resolution of SuperDARN data. However, this is not the case because the beams of the Alaska and British Columbia radars are sampled at different times and the bursts should have been observed at least on a few of the beams, if not all.

[34] Large magnetic perturbations are also observed during the injections. Figures $8 \mathrm{~d}-8 \mathrm{f}$ show the time varia- tions of the magnetic field and parallel current measured at Cluster-1 during the pressure pulse. Figure 8d displays the modulus of the magnetic field. In addition to the general decrease, due to the increasing altitude of the satellite, the variations of the modulus of the magnetic field are the result of two effects. The first effect is the compression of the magnetosphere causing an increase in the magnetopause current, which affects the entire dayside magnetosphere. This effect is also observed at spacecraft 3 , which is situated on closed field lines at that time, and in the X component of ground magnetometers as the sudden impulse (SI). The second effect is the diamagnetic effect associated with the injections of plasma from the magnetosheath along the cusp field lines. This diamagnetic effect is observed at spacecraft 1 as a series of three reductions in the magnetic field strength, with decreasing amplitudes, that are simultaneous with the three plasma injections. The transverse component $\delta \mathbf{B}_{\perp}$ of the magnetic field is related to the parallel current. It has been calculated after having subtracted a polynomial fit to the FGM field components. The data were fitted from 0130 to 0133 UT and from 0145 to 0148 UT, respectively, before and after the compression and the plasma injections, in order to obtain the $\delta \mathbf{B}_{\perp}$ variations due to the injections alone. The polarization of this transverse field is nearly linear along a direction within $10^{\circ}$ of the isolatitude lines. Figure $8 \mathrm{e}$ shows the component of $\delta \mathbf{B}_{\perp}$ along this polarization direction, and Figure $8 \mathrm{f}$ shows the parallel current density deduced from the variation of $\delta \mathbf{B}_{\perp}$, assuming stationary infinite current sheets. During the first two injections in particular, one can discern a pair of upward and downward parallel current sheets as indicated by the gray-shaded zones. The density of these currents is large, reaching several tenths of $\mu \mathrm{A} / \mathrm{m}^{2}$, which corresponds to several tens of $\mu \mathrm{A} / \mathrm{m}^{2}$ if mapped to the ionosphere as DC currents, with the mapping factor of $\sim 100$ owing to the divergence of field lines. It must be noted that the assumption of stationary current sheets is not justified, and that the motion of the sheet should have been considered. A qualitative comparison of Figures $8 \mathrm{a}$ and $8 \mathrm{f}$ shows that the positive parallel currents are associated with an increased electron flux. By a careful analysis of the respective contributions of ions and electrons to the parallel current, and by assuming a plane current sheet moving with a constant velocity, BEF obtained a northward velocity of $\sim 5 \mathrm{~km} / \mathrm{s}$ for the current sheet at Cluster. Mapped to the ionosphere, the velocity is $500 \mathrm{~m} / \mathrm{s}$, which compares well (within a factor $\sim 1.5$ ) with the phase velocity of the PMRAFs. Although both velocities are related, this comparison must be considered with care because the Cluster measurements are performed during the injection period while SuperDARN phase velocity deduced from the slope of the PMRAFs is made later, during the fossil part of life of the structures. The determination of the integrated current (current density $\times$ sheet thickness) across the sheet given by $\delta \mathbf{B}_{\perp}$ and the location of the currents sheets shown on Figures 8e and 8f are independent of the assumed velocity of the current sheets.

\subsection{Mapping of Electric and Magnetic Fields From the Magnetosphere to the Ionosphere}

[35] We now consider the relationship between electric and magnetic measurements in the magnetosphere and in 

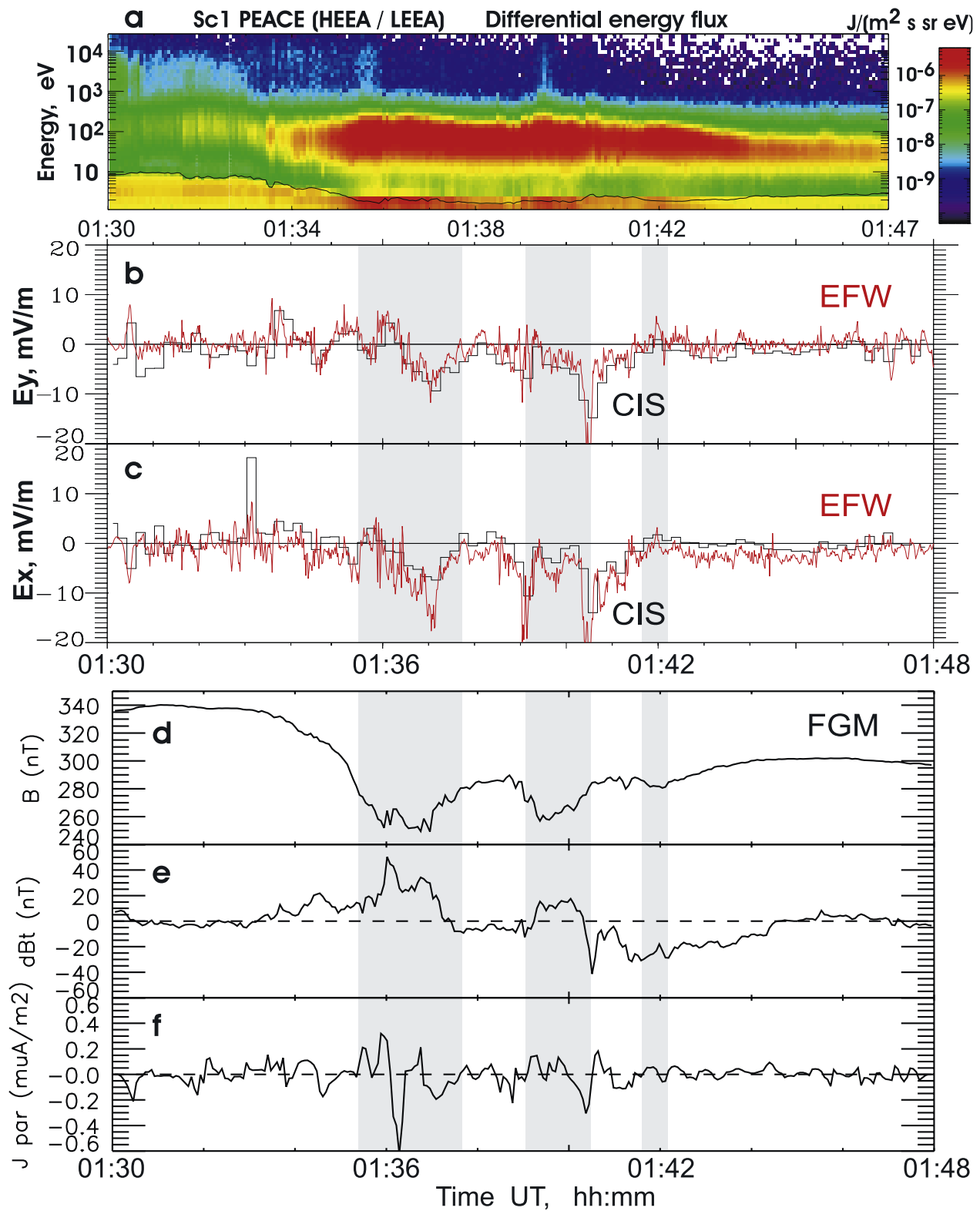

Figure 8. (a) Omnidirectional energy-time electron spectrogram during the second solar wind pressure pulse from Cluster-1 PEACE. The solid line shows the satellite potential measured by the EFW experiment. (b and c) GSE Y and X components of the electric field measured at Cluster-1 by the EFW experiment (red lines) and deduced from the CIS ion perpendicular velocity (black lines). (d-f) FGM data: Figure 8d displays the modulus of the magnetic field showing the diamagnetic effect of plasma injections; Figure 8e displays transverse magnetic component along the mean polarization direction; and Figure $8 \mathrm{f}$ displays parallel current density (positive upward) deduced from the transverse components of the magnetic field.

the ionosphere. Two basic coupling mechanisms between these two regions can be considered, either a static mapping or a coupling by Alfvén waves.

[36] In the case of a static mapping and in the absence of parallel electric fields, the magnetospheric convection electric fields, as well as the convection velocities, map perfectly into the ionosphere. The mapping factor between Cluster and the ionosphere is close to 10 for the electric field regardless of its direction and $10^{-1}$ for the velocity. From Figure 7, the Cluster EDI and SuperDARN data are in good agreement showing that, after the injection events, the static mapping is effectively observed with a northward convection velocity component of the order of $800 \mathrm{~m} / \mathrm{s}$ in the ionosphere. Although the agreement is less satisfactory for the British Columbia radar, both evaluations remain within a factor of 2. Furthermore, the agreement between CIS-EFW and SuperDARN is also good (see BEF, their Figure 6) after the injections. However, during injections the strong enhancements in the electric field at Cluster (Figures $8 \mathrm{~b}$ and $8 \mathrm{c}$ ) observed by CIS and EFW should map in the static model as westward velocities of the order of $2-3 \mathrm{~km} / \mathrm{s}$. If mapped to the ionosphere, such large 
velocities should be clearly visible as aliased measurements in the SuperDARN data. The absence of such aliased signatures shows without any doubt that these large velocities do not map down to the ionosphere.

[37] Another argument against the static hypothesis is the inconsistency between electric and magnetic measurements. Although the amplitude of the parallel current density shown in Figure $8 \mathrm{f}$ depends upon the assumed velocity of the current sheet, the integrated current across the sheet is well determined by the transverse magnetic variation which amounts typically to $\delta B=20 \mathrm{nT}$. In a static model of localized reconnection [Southwood, 1987], the parallel current is closed by a Pedersen current in the lower ionosphere and, taking into account the divergence of field lines, the reconnected flux tube moves with a velocity $V_{I}=$ $\delta B /\left(\mu_{0} \Sigma_{P} \sqrt{B_{C} B_{I}}\right)$ in the ionosphere. In this relation, $\Sigma_{P}$ is the integrated Pedersen conductivity, $B_{C}$ and $B_{I}$ represent the magnetic field at Cluster and in the ionosphere, respectively. For the Pedersen conductivity, the contribution due to solar ionization [Senior, 1991] for the prevailing solar zenith angle is $\Sigma_{P}^{E U V}=6 S$, while, from Galand and Richmond [2001], the proton contribution is $\Sigma_{P}^{H^{+}}=$ $5.7 Q_{H^{+}}{ }^{0.5}$ where $Q_{H^{+}}$is the energy density in $\mathrm{mW} \mathrm{m} \mathrm{m}^{-2}$. From the Hot Ion Analyzer (CIS/HIA), $Q_{H^{+}}=1.5 \mathrm{~mW} \mathrm{~m}^{-2}$, which gives the proton contribution $\Sigma_{P}^{H^{+}}=7.0 \mathrm{~S}$. The total Pedersen conductivity is thus $\Sigma_{P}=\left(\Sigma_{P}^{H^{+2}}+\Sigma_{P}^{E U V^{2}}\right)^{0.5}=9.2 S$. For $B_{C}=300 \mathrm{nT}$ and $B_{I}=50,000 \mathrm{nT}$, one obtains $V_{I}=$ $450 \mathrm{~m} / \mathrm{s}$. This value is much smaller (by a factor 5 to 8 ) than the longitudinal convection velocity deduced from the direct mapping of the $\mathrm{E}_{\mathrm{y}}$ component of the electric field measured by CIS and EFW during the injection events. Although the error in the estimated Pedersen conductivity may be large, it is difficult to reconcile the estimated and the Cluster velocities during the injections.

[38] Alfvén waves are supposed to be responsible of momentum transfer from the reconnection site to the ionosphere. Recently, Farrugia et al. [2004] have clearly demonstrated the presence of Alfvén waves along a reconnected flux tube observed both in the outer cusp and in the ionosphere. In the present case and contrary to the static hypothesis, we demonstrate below that the Alfvén wave interpretation leads to a more realistic relationship between electric and magnetic measurements in the magnetosphere and in the ionosphere. At Cluster-1, let us now assume that the plasma injections from the magnetosheath are accompanied by a shear Alfvén wave. The Alfvén velocity $C_{A}$ can be evaluated either from the ratio of the electric to the magnetic perturbations $\delta E / \delta B=C_{A}$, or from the plasma density and magnetic field $B_{0} /\left(\rho \mu_{0}\right)^{1 / 2}=C_{A}$. For the injection observed at $0136 \mathrm{UT}$, with the measured numerical values $B_{0}=300 \mathrm{nT}$, $\delta E=10 \mathrm{mV} / \mathrm{m}, \delta B=20 \mathrm{nT}$ and a plasma density $\rho$ measured both by PEACE and CIS of $120 \mathrm{~cm}^{-3}$, the two corresponding values of the Alfvén velocity are respectively 500 and $600 \mathrm{~km} / \mathrm{s}$. The consistency between these two independent estimates supports the Alfvén wave hypothesis.

[39] The Alfvén wave interpretation can also explain the absence of observation of the large electric field in the ionosphere, the downgoing Alfvén wave being partly reflected in the topside ionosphere. An estimate of the reflection coefficient can be obtained from its value in the absence of transverse gradients $|R|=\left|\left(\Sigma_{A}-\Sigma_{P}\right) /\left(\Sigma_{A}+\Sigma_{P}\right)\right|$ [see, e.g., Lysak and Song, 2000] where $\Sigma_{A}$ and $\Sigma_{P}$ are respectively the Alfvén and ionospheric Pedersen conductances. Numerically, from the above values of the Alfvén velocity, $\Sigma_{A}=1 / \mu_{0} C_{A}=1.4 S$. For the previously calculated Pedersen conductivity $\Sigma_{P}=9.2 S$, the reflection coefficient becomes $R=0.74$. Thus only a small fraction of the transverse electric perturbation is transmitted to the lower ionosphere. This can explain why only a slight increase in the ionospheric convection velocity was observed during the injection events. This is, for instance, clear in Figure 7b for the Alaska measurement at 0137 UT.

[40] In the previous discussion, we did not consider the possibility of imperfect electric field mapping due to fieldaligned potential drops below Cluster. Being situated above the acceleration region, Cluster observations are of no help to confirm or exclude their existence. Let us observe however that parallel potential drops are necessary if we want to reconcile the present observations with the static model. It is not the case for the Alfvén wave model although kinetic effects may occur which support parallel electric fields.

\section{Summary and Conclusions}

[41] We have analyzed coordinated observations in the midaltitude (4-5 Re) cusp by Cluster and at its ionospheric magnetic footprint by SuperDARN and IMAGE during a period of three successive solar wind dynamic pressure pulses. Associated with each of these pulses, Cluster observed plasma injections, while the auroral images from the IMAGE spacecraft show enhanced precipitation in the cusp. Following these plasma injections, convection flow channels were observed in the ionosphere by the SuperDARN radars. The spatial and temporal relation between these various signatures has been established, leading to a coherent description of the response of the dayside magnetosphere to the pressure pulse. The main results of the present study are:

[42] 1. The solar wind dynamic pressure pulses triggered enhanced reconnection at the magnetopause causing plasma injections from the magnetosheath into the cusp. This conclusion, also reached by BEF in their analysis of the same event, is confirmed by the similarities between the flow bursts described in this paper and the poleward moving radar auroral forms obviously triggered by variations of the IMF orientation.

[43] 2. The convection bursts in the ionosphere started shortly after the auroral intensifications and their duration of 10 min was much longer than the 4-6 min duration of the auroral intensifications. Spatially, the convection bursts do not occur at the same latitude as the precipitation, but on the poleward side of the cusp precipitation. These observations are consistent with the image of the convection bursts being a "fossil" signature of the compression-injection process.

[44] 3. The electric field of the Alfvén waves, which transmit the magnetic stress downward from the reconnection site, is not transmitted into the ionosphere but is reflected above the ionosphere due to the mismatch between the Alfvén and the Pedersen conductances, although the presence of parallel potential drops during injections may also play a role.

[45] Acknowledgments. The SuperDARN radars in Alaska and British Columbia are operated by the University of Alaska and the 
University of Saskatchewan, respectively. We thank E. Dore at LANL for the use of LANL L4 high-energy proton data provided through CDA Web. We thank also N. Ness at Bartol Research Institute and D. J. McComas at LANL for the use of ACE magnetometer and solar wind data provided also through CDA Web.

[46] Arthur Richmond thanks Stephen Milan and Michael Pinnock for their assistance in evaluating this manuscript

\section{References}

Balogh, A., et al. (2001), The Cluster magnetic field investigation: Overview of in-flight performance and initial results, Ann. Geophys., 19, $1207-1217$

Bosqued, J.-M., et al. (2005), Multipoint observations of transient reconnection signatures in the cusp precipitation: A Cluster-IMAGE detailed case study, J. Geophys. Res., 110, A03219, doi:10.1029/2004JA010621.

Davies, J. A., T. K. Yeoman, I. J. Rae, S. E. Milan, M. Lester, M. Lockwood and K. A. McWilliams (2002), Ground-based observations of the auroral zone and polar cap ionospheric responses to dayside transient reconnection, Ann. Geophys., 20, 781-794.

Farrugia, C. J., P.-E. Sandholt, S. W. H. Cowley, D. J. Southwood A. Egeland, P. Stauning, R. P. Lepping, A. J. Lazarus, T. Hansen, and E. Friis-Christensen (1995), Reconnection-associated auroral activity stimulated by two types of upstream dynamic pressure variations: Interplanetary magnetic field $\mathrm{Bz} \sim 0$, By $\ll 0$ case, J. Geophys. Res., 100, $21,753-21,772$

Farrugia, C. J., et al. (2004), Pulsed flows at the high-altitude cusp poleward boundary, and associated ionospheric convection and particle signatures, during a Cluster - FAST - SuperDARN - Søndrestrøm conjunction under a southwest IMF, Ann. Geophys., 22, 2891-2905.

Frey, H. U., S. B. Mende, S. A. Fuselier, T. J. Immel, and N. Østgaard (2003), Proton aurora in the cusp during southward IMF, J. Geophys. Res., 108(A7), 1277, doi:10.1029/2003JA009861.

Friis-Christensen, E., S. Vennerstrom, M. A. McHenry, and C. R. Clauer (1988), Ionospheric traveling convection vortices observed near the polar cleft-A triggered response to sudden changes in the solar wind, Geophys. Res. Lett., 15, 253-256.

Galand, M., and A. D. Richmond (2001), Ionospheric electrical conductances produced by auroral proton precipitation, J. Geophys. Res., 106(A1), 117-125.

Glassmeier, K.-H., M. Hoenisch, and J. Untiedt (1989), Ground-based and satellite observations of traveling magnetospheric convection twin vortices, J. Geophys. Res., 94, 2520-2528.

Greenwald, R. A., et al. (1995), DARN/SuperDARN: A global view of high latitude convection, Space Sci. Rev, 71, 763-796.

Gustafsson, G., et al. (1997), The electric and wave experiment for the Cluster mission, Space Sci. Rev., 79, 137-156.

Johnstone, A. D., et al. (1997), PEACE: A plasma electron and current experiment, Space Sci. Rev., 79, 351-398

Lockwood, M., S. W. H. Cowley, P. E. Sandholt, and R. Lepping (1990), The ionospheric signatures of flux transfer events and solar wind dynamic pressure changes, J. Geophys. Res., 95, 17,113-17,135.

Lysak, R. L., and Y. Song (2000), The role of Alfvén waves in the formation of auroral parallel electric fields, in Magnetospheric Current Systems, Geophys. Monogr. Ser, vol. 118, edited by S. Ohtani et al., pp 147-155, AGU, Washington, D. C.

Marchaudon, A., J.-C. Cerisier, J.-M. Bosqued, M. W. Dunlop, J. A. Wild, P. M. E. Décréau, M. Förster, D. Fontaine, and H. Laakso (2004), Transient plasma injections in the dayside magnetosphere: One-to-one correlated observations by Cluster and SuperDARN, Ann. Geophys., $22,141-158$

McWilliams, K. A., T. K. Yeoman, and S. W. H. Cowley (2001), Twodimensional electric field measurements in the ionospheric footprint of a flux transfer event, Ann. Geophys., 18, 1584-1598.

Mende, S. B., et al. (2000), Far ultraviolet imaging from the IMAGE spacecraft. 3 Spectral imaging of Lyman- $\alpha$ and OI $135.6 \mathrm{~nm}$, Space Sci. Rev., 91, 287-318

Milan, S. E., M. Lester, S. W. H. Cowley, J. Moen, P. E. Sandholt, and C. J. Owen (1999), Meridian-scanning photometer, coherent HF radar, and magnetometer observations of the cusp: A case study, Ann. Geophys., 17, $159-172$

Milan, S. E., M. Lester, S. W. H. Cowley, K. Oksavik, M. Brittnacher, R. A Greenwald, G. Sofko, and J.-P. Villain (2003), Variations in the polar cap area during two substorm cycles, Ann. Geophys., 21, 1121-1140.

Newell, P. T., and C.-I. Meng (1994), Ionospheric projection of magnetospheric regions under low and high solar wind pressure conditions, J. Geophys. Res., 99, 273-286.
Paschmann, G., et al. (2001), The electron drift instrument on Cluster: Overview of first results, Ann. Geophys., 19, 1273-1288.

Provan, G., S. E. Milan, M. Lester, T. K. Yeoman, and H. Khan (2002), Simultaneous observations of the ionospheric footprint of flux transfer events and dispersed ion signatures, Ann. Geophys., 20, 281-287.

Rème, H., et al. (2001), First multispacecraft ion measurements in and near the Earth's magnetosphere with the identical Cluster ion spectrometry (CIS) experiment, Ann. Geophys., 19, 1303-1354.

Roelof, E. C., and D. G. Sibeck (1993), Magnetopause shape as a bivariate function of interplanetary magnetic field $B z$ and solar wind dynamic pressure, J. Geophys. Res., 98, 21,421-21,450.

Ruohoniemi, J. M., and K. B. Baker (1998), Large-scale imaging of the high-latitude convection with Super Dual Auroral Radar Network HF radar observations, J. Geophys. Res., 103, 20,797-20,812.

Sandholt, P. E., J. Moen, A. Rudland, D. Opsvik, W. F. Denig, and T. Hansen (1993), Auroral event sequences at the dayside polar cap boundary for positive and negative interplanetary magnetic field $B y$, J. Geophys. Res., 98, 7737-7755.

Sandholt, P. E., et al. (1994), Cusp/cleft auroral activity in relation to solar wind dynamic pressure, interplanetary magnetic field $B z$ and $B y$, J. Geophys. Res., 99, 17,323-17,342.

Senior, C. (1991), Solar and particle contributions to auroral heightintegrated conductivities from EISCAT data-A statistical study, Ann. Geophys., 9, 449-460.

Shepherd, S. G., and J. M. Ruohoniemi (2000), Electrostatic potential patterns in the high-latitude ionosphere constrained by SuperDARN measurements, J. Geophys. Res., 105, 23,005-23,014.

Sibeck, D. G., and D. J. Croley Jr. (1991), Solar wind dynamic pressure variations and possible ground signatures of flux transfer events, J. Geophys. Res., 96, 1669-1683.

Sibeck, D. G., R. E. Lopez, and W. J. Baumjohann (1989), Solar wind dynamic pressure variations and transient magnetospheric signatures, Geophys. Res. Lett., 16, 13-16.

Sibeck, D. G., N. B. Trivedi, E. Zesta, R. B. Decker, H. J. Singer, A. Szabo, H. Tachihara, and J. Watermann (2003), Pressure-pulse interaction with the magnetosphere and ionosphere, J. Geophys. Res., 108(A2), 1095, doi:10.1029/2002JA009675.

Song, P., G. Le, and C. T. Russell (1994), Observational differences between flux transfer events and surface waves at the magnetopause, J. Geophys. Res., 99, 2309-2320.

Southwood, D. J. (1987), The ionospheric signature of flux transfer events, J. Geophys. Res., 92, 3207-3213.

Thorolfsson, A., J.-C. Cerisier, M. Lockwood, P. E. Sandholt, C. Senior, and M. Lester (2000), Simultaneous optical and radar signatures of poleward moving auroral forms, Ann. Geophys., 18, 1054-1066.

Tsyganenko, N. A. (1995), Modeling the earth's magnetospheric magnetic field confined within a realistic magnetopause, J. Geophys. Res., 100, $5599-5612$

Wild, J. A., et al. (2001), First simultaneous observations of flux transfer events at the high-latitude magnetopause by the Cluster spacecraft and pulsed radar signatures in the conjugate ionosphere by the CUTLASS and EISCAT radars, Ann. Geophys., 19, 1491-1508.

Zhou, X., and B. T. Tsurutani (1999), Rapid intensification and propagation of the dayside aurora: Large scale interplanetary pressure pulses (fast shocks), Geophys. Res. Lett., 26, 1097-1100.

J.-M. Bosqued, Centre d'Etudes Spatiales des Rayonnements, 9 Av. Colonel Roche, BP4346, F-31028 Toulouse Cedex 4, France.

M. Bouhram and J.-C. Cerisier, Centre d'Etude des Environnements Terrestre et Planétaires, 4 Av. Neptune F-F-94107 Saint-Maur, France. (jean-claude.cerisier@cetp.ipsl.fr)

M. Dunlop, Space Science and Technology Department, Rutherford Appleton Laboratory, Chilton, Didcot OX1 0QX, UK.

A. Fazakerley and A. Marchaudon, Mullard Space Science Laboratory, University College London, Holmbury St Mary, Dorking RH5 6NT, UK.

M. Förster, Max-Planck-Institut für extraterrestrische Physik, P.O. Box 1312, D-85741 Garching, Germany.

H. U. Frey, Space Sciences Laboratory, University of California, Grizzly Peak Boulevard, Berkeley, CA 94720, USA.

H. Laakso, Space Science Department, ESA/ESTEC, Postbus 299, Keplerlaan, 1, N-2200 AG Noordwijk, Netherlands.

K. McWilliams, Institute of Space and Atmospheric Studies, University of Saskatchewan, 116 Science Place, Saskatoon, SK S7N 5E2, Canada. 